\title{
A 1,000-year chain of thinkers
}

\author{
....Kant is connected to Abel, Abel's connected to Maxwell ...
}

\section{Giovanni F. Bignami}

cience, and indeed thought, at the dawn of the second Christian millennium blossomed in the Arabic world. Abdulla ibn Sina (980-1037) — known to the west as Avicenna - opens the millennium with his first philosophical work in 1001. Over the next 30 years, he produced the five books of the Qanun, which became the best-known and most respected medical treatise up to the seventeenth century, translated and reprinted in more than 80 versions. The first 200 years of the millennium are dominated by eclectic Arab thinkers, scientists as much as elegant writers and poets, such as Omar Khayyàm (1050-1126), followed by Averroës (1126-98), as the philosopher and physician ibn Rushd is known to the infidels.

In a nearly perfect junction between the Arab and the Christian worlds, Frederick II was born in 1195 . He was to radiate from southern Italy the new light of thought, science and the arts. He lived in the very years when fighting the Crusades was very holy, very bloody and very lucrative: a centurieslong example of unsurpassed military and political futility.

In sharp contrast to the Crusaders' fanatical clashes stands Marco Polo (1254-1324), ambassador of reason towards the East. Ironically, it is thanks to the Venetians' defeat in battle by the Genoese that we have Polo's splendid accounts of his 24 years of travel to Catai and beyond: it was all written while he languished in a Genoese prison.

The death of Polo in 1324 brings a difficult century to our chain, whose links are now plagued by the Black Death of 1348 . And yet fundamental thought blossomed more strongly than ever in the 1300 s with the great schools of Oxford and Cambridge and the 'physics' school of Paris. As a representative single link we pick Albert of Saxony, bishop of Halberstadt (c.1325-c.1398). Professor in Paris until 1362, he then moved on to become the first rector of the University of Vienna, thus acting as a cultural link between West and East in Europe. In contrast, we open the 1400s with an artisan - a goldsmith, and not especially well-read. Johannes Gutenberg (1398-1468) applied the medallist's technique for dies to create 'type' (from the Greek 'to strike'). Born to fulfil the prosaic needs of merchant bookkeepers, printing was soon to change the face of the world as, half a millennium later, would the computer and the web.

A seven-year gap seems a small price

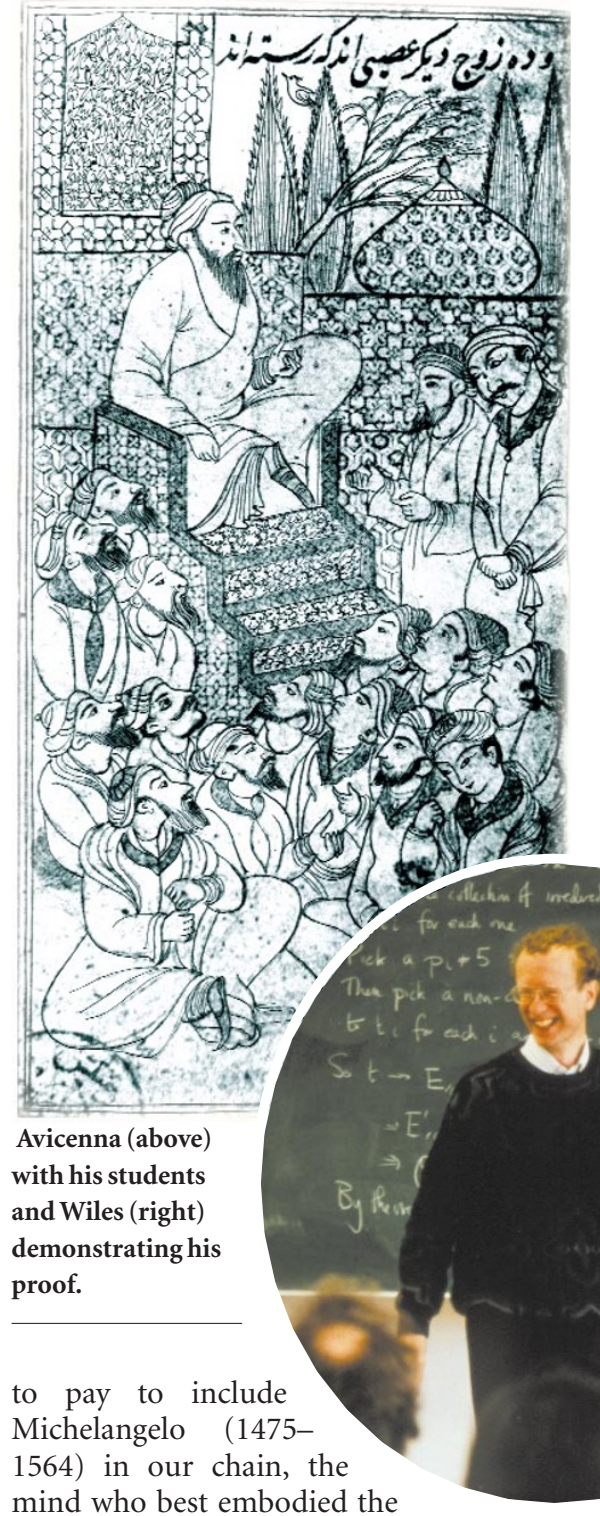
mind who best embodied the

Renaissance in Europe. Artist, writer, architect, but also skilled anatomist and more, we have all inherited a spark of his vision of beauty. Lesser known is Michelangelo's political vision, which included saying 'no' to Popes and getting away with it. What an omen then, that he died, they say, on the very day that Galileo Galilei (1564-1642) was born. To Galileo we owe the modern scientific method and a capacity to express it elegantly, down to his "Eppur si muove" credited, we like to think, to an old man forced to recant in word but not in spirit.

In the very last days of 1642 or the first of 1643 , depending on calendars, Isaac Newton (1642-1727) was born. Within the manifold aspect of his genius, his truly gigantic leap was to see that the same natural laws that

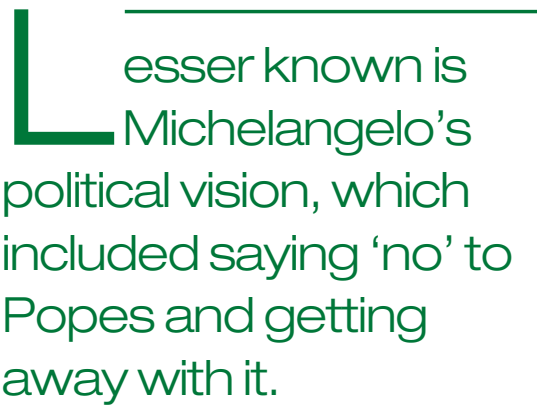

we observe around us are also true for planets, stars and the Universe. When Newton died, Immanuel Kant (1724-1804) was a child of three, growing up in an evolving eighteenth-century continental Europe, where his philosophy bloomed and spread, to change our thought for ever.

From 1804 to the quasi-present (1955), two parallel sub-chains are possible. One starts with the Norwegian mathematician Niel Abel (1802-29), who died in abject poverty of tuberculosis at 26 , and yet it is said that he paved the way for mathematicians for the next 500 years. Just after Abel died, the greatest theoretical physicist of the nineteenth century was born: James Clerk Maxwell (1831-79). Besides the first quantitative unified description of the electromagnetic field, few remember that he also produced the first colour photograph. Finally, in the year of Maxwell's death, Albert Einstein (1879-1955) was born, to become the greatest theoretical mind of the twentieth century.

The other path starts with Charles Darwin (1809-82), to whom we owe a scientific revolution comparable only to that of Copernicus and Galileo. When Darwin died, Alexander Fleming (1881-1955) had just been born to a destiny of fame through his serendipitous (but lucidly understood) discovery of a miraculous mould.

We end our millennium chain with mathematician Andrew Wiles (born 1953): his recent proof of Fermat's Last Theorem pleases the scientist as much as the historian, closing a thought-link that had remained open for over three centuries.

Giovanni F. Bignami is with the Italian Space

Agency, Via di Villa Patrizi 13, Rome 00161, Italy. 